\title{
Pref-1, a gatekeeper of adipogenesis
}

\section{Carolyn S. Hudak and Hei Sook Sul*}

Department of Nutritional Sciences and Toxicology, University of California, Berkeley, CA, USA

\section{Edited by:}

Encarnación Capilla, University of Barcelona, Spain

Reviewed by:

Chris K. C. Wong, Hong Kong Baptist University, China

Stephen Robert Farmer, Boston

University School of Medicine, USA

\section{*Correspondence:}

Hei Sook Sul, Department of

Nutritional Sciences and Toxicology,

University of California, 219 Morgan

Hall, Berkeley, CA 94720, USA

e-mail: hsul@berkeley.edu
Preadipocyte factor 1 (Pref-1, also called DIk1/FA1) is a molecular gatekeeper of adipogenesis which acts by maintaining the preadipocyte state and preventing adipocyte differentiation. Pref- 1 is made as an epidermal growth factor-like repeat containing transmembrane protein, and is cleaved by TNF $\alpha$-converting enzyme (TACE) to generate a soluble form, which acts as an autocrine/paracrine factor. Pref- 1 upregulates Sox9 expression by activating the ERK/MAPK pathway and the Pref-1 interaction with fibronectin is required for inhibition of adipogenesis. Pref- 1 also prevents brown adipocyte differentiation and its thermogenic function. Here, we highlight the recent evidence for the role of Pref- 1 in adipogenesis.

Keywords: Pref-1, adipogenesis, brown fat, progenitors, fibronectin, SOX9 transcription factor
Obesity, characterized by an increase in white adipose tissue (WAT) mass, has become a major health problem on an epidemic scale and is associated with increased risk of various diseases, such as cardiovascular diseases and diabetes. Throughout the lifespan, adipose tissue not only expands through hypertrophy of existing adipocytes, but also through hyperplasia of preadipocytes differentiating into adipocytes. Various factors that affect differentiation have been identified. However, despite major advances in adipose biology, the underlying processes and mechanisms for adipose tissue development and its expansion are not fully understood. In addition, with the recent evidence of the presence of functional brown adipose tissue (BAT) in adults, implicating its potential as a therapeutic target for obesity, attention has been focused on understanding the development of BAT, which dissipates energy, in contrast to WAT that serves as the major energy storage organ.

\section{ADIPOCYTE DIFFERENTIATION}

Adipose tissue contains heterogeneous cell types. In addition to lipid filled adipocytes, adipose tissue contains the so-called stromal vascular fraction (SVF) composed of preadipocytes, macrophages, endothelial cells, and other fibroblast-like cells. Primary preadipocytes and preadipocyte cell lines, such as 3T3L1 and 3T3-FT442A cells, undergo differentiation in the presence of adipogenic media containing dexamethasone (DEX), isobutylmethylxanthine (IBMX), and insulin and the differentiation process has been extensively studied at the transcriptional level. Intricate coordination of various transcription factors is required for differentiation. CCAAT/enhancer binding protein $\beta$ $(\mathrm{C} / \mathrm{EBP} \beta)$ and $\mathrm{C} / \mathrm{EBP} \delta$ are induced early during differentiation and activate peroxisome proliferator-activated receptor $\gamma(\operatorname{PPAR} \gamma)$ and $\mathrm{C} / \mathrm{EBP} \alpha . \operatorname{PPAR} \gamma$, is necessary and sufficient to promote adipocyte differentiation, and treatment with PPAR $\gamma$ agonists, thiazolidinediones, can promote differentiation in vitro (1). Since the discovery of PPAR $\gamma$, many additional transcription factors that play a role in adipocyte differentiation have been identified and have been extensively reviewed elsewhere (2-7). Recent research has been devoted to identifying unique markers of preadipocytes or adipose progenitors. In this regard, ZFP423 has been reported to be critical for the preadipocyte commitment process (8). And, PRDM16 has been identified as a major player in the differentiation of brown adipocytes (9).

Not only does adipose tissue play a critical role in energy metabolism by being the major energy storage organ, it also secretes and responds to a variety of molecules involved in energy homeostasis, immunity, and vascular function. The role of leptin and adiponectin, two cytokines that are secreted by adipocytes and regulate energy homeostasis, have been well described elsewhere $(10,11)$. Inflammatory cytokines such as TNF- $\alpha$ and IL-6 are also secreted from adipocytes (12). TNF $\alpha$ may help recruit mesenchymal precursors from other organs to the adipose tissue, which may then undergo differentiation to form new adipocytes (13). We originally identified Preadipocyte factor- 1 [Pref- 1 ; also called Dlk1 (Delta-like protein-1), fetal antigen-1 (FA1)] as a preadipocyte factor that prevents adipocyte differentiation and Pref- 1 expression is decreased during differentiation to allow adipogenesis (1416). While many of the adipose related cytokines are secreted from adipocytes, Pref- 1 is produced by preadipocytes and acts in an autocrine/paracrine fashion. This review highlights recent advances in the knowledge of the role of Pref- 1 in the regulation of adipocyte differentiation and its signaling mechanism, as well as its effects on BAT.

\section{PREF-1 STRUCTURE AND SIGNALING}

Pref- 1 is synthesized as a transmembrane protein that contains six EGF-like repeats at the extracellular domain $(17,18)$. These repeats maintain the conserved spacing to form three disulfide bonds from six cysteine residues (19). Upon proteolytic cleavage by TNF- $\alpha$ converting enzyme (TACE), multiple soluble forms of Pref- 1 are generated and the larger $50 \mathrm{kDa}$ form is biologically active. Pref- 1 cleavage by TACE can be inhibited by GM6001, a broad metalloproteinase inhibitor, indicating that Pref-1 cleavage is dependent on metalloproteinase activity, and this activity 
is enhanced by phorbol ester treatment, showing that Protein Kinase $\mathrm{C}$ may regulate Pref-1 cleavage. Though DEX treatment down-regulates Pref-1 expression, regulation of Pref-1 activity may also occur at the proteolytic cleavage step (20).

We demonstrated that Pref-1 rapidly induces Sox9 expression through activation of the MEK/ERK pathway (21). Thus, Sox9 constitutive overexpression can inhibit adipocyte differentiation. Downregulation of Pref- 1 during differentiation coincides with increased $\mathrm{C} / \mathrm{EBP} \beta$ and $\mathrm{C} / \mathrm{EBP} \delta$, which occurs prior to $\mathrm{C} / \mathrm{EBP} \alpha$ and PPAR $\gamma$ induction. Induction of Sox 9 by Pref- 1 during adipocyte differentiation is at the very early stage, and Sox 9 acts to maintain cells in a preadipocyte state by suppressing transcription of $\mathrm{C} / \mathrm{EBP} \beta$ and $\mathrm{C} / \mathrm{EBP} \delta$ by directly binding to their promoter regions. We also found that Pref- 1 not only inhibits adipogenesis, but promotes chondrogenic commitment (21). In this regard, Sox9 has been known to function in chondrogenesis, and Sox9 ablation in mice results in the prevention of cartilage formation. We have observed that, like Sox9, ablation of Pref-1 causes malformation of skeletons in mice. Pref- 1 causes inhibition of osteoblast differentiation, also via its induction of Sox 9 that in turn prevents expression of an osteogenic transcription factor, Runx2. These similar in vitro and in vivo effects observed further demonstrate that physiological effects of Pref- 1 are mediated via its induction of Sox 9 expression.

The mechanistic details of the Pref-1 signaling pathway have been recently uncovered. Although it has been proposed that Pref1 may function in the Notch signaling pathway due to the presence of EGF repeats (22,23), Pref-1 lacks the Delta:Serrate:Lin-12 (DSL) domain that is required to mediate activation of Notch. Furthermore, we found that there is no direct interaction between Pref-1 and Notch, nor were there any changes in the expression of a downstream target of Notch, Hes-1, by Pref-1. Though the putative Pref- 1 receptor is yet to be identified, we found that Pref- 1 interacts with fibronectin (24). The Pref-1 interaction with the C-terminal domain of fibronectin is necessary for the Pref- 1 inhibition of adipocyte differentiation. Several growth factors are known to bind various regions of fibronectin for modulation of growth factor function. Furthermore, fibronectin was shown previously to prevent adipocyte differentiation $(25,26)$. We found that knockdown of fibronectin or addition of Pref- 1 interacting domains of fibronectin prevent the Pref- 1 mediated activation of MEK/ERK and Sox9 induction, resulting in enhancement of adipocyte differentiation. Furthermore, knockdown of the $\alpha 5$ of the major integrin in preadipocytes, $\alpha 5 \beta 1$, or treatment with RGD peptide which blocks the fibronectin interaction, prevent the Pref-1 inhibitory action on adipocyte differentiation. Pref-1-fibronectinintegrin interaction activates the FAK/Src complex and Rho-like GTPases, which can then activate the ERK/MAPK pathway (27). Overall, Pref-1 directly binds fibronectin and activates integrin signaling through ERK/MAPK to inhibit adipocyte differentiation (24) (Figure 1).

\section{ROLE OF PREF-1 DURING ADIPOGENESIS}

As described above, Pref-1 was originally identified as an inhibitor of adipocyte differentiation and its effect on WAT development has been well documented in vitro and in vivo. Overexpression of Pref-1 in 3T3-L1 preadipocytes drastically lowers the degree of adipocyte differentiation, and knocking down Pref-1 greatly increases differentiation $(14,28)$. Furthermore, we have generated Pref-1 null mice as well as transgenic mice overexpressing Pref1 (29-31). Pref-1 null mice have increased adiposity and also higher mRNA levels of adipocyte markers. On the other hand, mice overexpressing Pref-1 have decreased adipose mass and decreased adipocyte marker expression. As observed in lipodystrophy models, these mice also have hypertriglyceridemia, decreased glucose tolerance, and lower insulin sensitivity (31). We can conclude that Pref-1 clearly affects adipogenesis.

The role of Pref-1 in BAT has not been well explored. As in WAT, however, it is known that Pref- 1 is downregulated during BAT development, being present at a very high level in fetuses but decreasing to an undetectable level several weeks after birth (32). Though BAT appeared to be normal prior to birth, Pref- 1 ablated mice show altered BAT morphology after birth, with potential thermogenic over-activation, indicated by the induction of thermogenic markers and enhanced lipid mobilization. Conversely, in lipodystrophy mouse models, Pref- 1 is expressed at a higher level in BAT, which is associated with loss of thermogenesis and increased lipid accumulation (33). An indirect mechanism of this effect may be through the DEX-mediated induction of $\mathrm{C} / \mathrm{EPB} \delta$, as was recently demonstrated by Armengol et al. (32). Taken together, these results demonstrate that Pref- 1 plays an important role in the regulation of both WAT and BAT differentiation.

Dexamethasone suppresses Pref-1 expression in preadipocytes allowing for the eventual induction in PPAR $\gamma$ expression and differentiation of preadipocytes into adipocytes. Though the adipocyte differentiation process has been well studied, little is known about the transition steps from embryonic stem cells (ESC) or mesenchymal stem cells (MSC) to preadipocytes (34). A potential role of Pref-1 in the commitment stage of adipogenesis has been revealed via the use of MSCs. These pluripotent MSCs can differentiate into adipocytes upon treatment with IBMX and DEX. It has recently been reported that IBMX increases Pref- 1 expression initially (35), followed by a DEX-mediated decrease in Pref-1 expression, showing a transient rise in the Pref-1 level in MSCs at the commitment stage prior to adipocyte differentiation. Similarly, during differentiation of human fetal MSCs into adipocytes, the Pref- 1 expression level rose early in the differentiation process but decreased in the later stages. Furthermore, epinephrine treatment in mouse ESC was reported to induce Pref-1 expression and cell proliferation. Interestingly, the Pref- 1 level was increased at the commitment stage, indicating that epinephrine may induce cells to become committed to the adipocyte lineage. This effect could be reversed by treatment with antagonists of the Neuropeptide Y (NPY) receptor (36). These observations together suggest that commitment to the adipocyte lineage involves Pref-1 induction (37), and Pref-1 may be used as a marker for precursors of adipogenesis.

The identity of adipose precursors remains an active area of research. Lineage tracing has often been used to understand the developmental origin of various cell types (38-40). By using the PPAR $\gamma$ locus, Tang et al. (41) first showed that adipose progenitors express PPAR $\gamma$, and they reside near the vasculature. However, PPAR $\gamma$ is expressed not only in preadipocytes but also in differentiated adipocytes, which makes it tricky to discern adipose precursors. Regardless, other recent reports also indicate that 


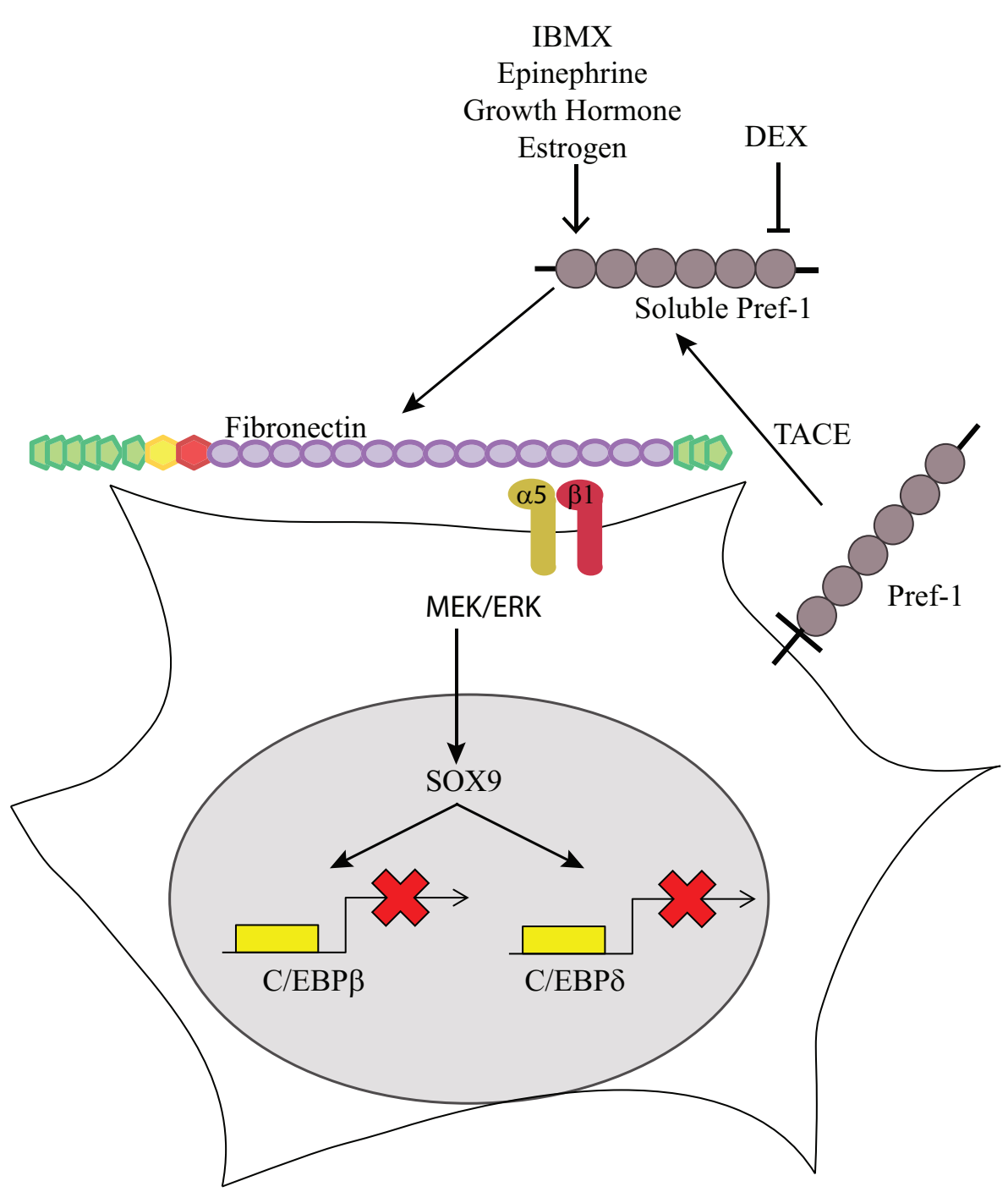

FIGURE 1 | Pref-1 inhibition of adipogenesis. Membrane bound Pref- 1 is cleaved by TACE to generate a 50 kDa soluble factor. Pref- 1 interacts with fibronectin and via integrin $\alpha 5 \beta 1$ activates MEK/ERK, which increases Sox9, which then binds to the promoter regions of
C/EBP $\beta / \delta$ to block adipocyte differentiation. Dexamethasone has been shown to decrease Pref-1 expression while IBMX, epinephrine, growth hormone and estrogen have been shown to increase Pref-1 expression. adipocytes may come from endothelial cells or pericytes $(8,42$, 43). Adipocyte precursor cells were also identified in the adipose stroma using a combination of fluorescence-activated cell sorting. These cells were found to have a unique cell surface signature, including the presence of CD34, Sca-1, and CD24 (44). And, we recently employed Pref- 1 labeling to identify and characterize adipose precursors throughout development, as well as during diet induced expansion of WAT (Hudak and Sul, unpublished results).

In humans, Pref-1 has been recently shown to be clinically relevant and is associated with extreme early onset obesity. In trio studies of obese children and their biological parents, the association of Pref-1 with obesity became apparent only when considering imprinting of the gene, and supported the existence of polar overdominance in humans (45). Furthermore, in comparing Pref- 1 expression levels in metabolically healthy obese (MHO) and metabolically unhealthy obese (MUO) individuals, MHO patients had lower levels of Pref- 1 in their adipose tissue (46). These results indicated that metabolically healthy patients have increased preadipocyte differentiation which was also associated with a more favorable inflammatory profile. Therefore, MHO patients may have an increased number of smaller adipocytes, rather than increased adipocyte size, implying that increased adipocyte size may be an important process underlying metabolic disease in obesity.

\section{REGULATION OF PREF-1 EXPRESSION DURING ADIPOGENESIS}

Pref-1 is part of the imprinted gene cluster, Pref-1-Dio3 $(47,48)$. Ten imprinted genes have been identified in this cluster. There are three paternally expressed genes, Pref-1, Paternally Expressed 
Gene 11 [Peg11, also called Retrotransposon-like 1(Rtl1)] and type 3 deiodinase (Dio3), and seven maternally expressed genes coding for non-coding RNAs $(48,49)$. Interestingly, Pref- 1 is located in the same imprinted region as Dio3 (50), an inhibitor of T3, and changes in Dio3 expression levels during differentiation parallel that of Pref-1. Thyroid hormone is critical for BAT function and thermogenesis $(51,52)$, and T3 can stimulate brown adipocyte differentiation (53). Accordingly, DEX can suppress expression of both Dio3 and Pref-1 in cultured preadipocytes. In this regard, high levels of Dio3 have been detected in differentiating primary brown preadipocytes. Together, the coordinated expression of Pref- 1 and Dio3 further implicate the important role they may play during brown adipocyte differentiation (54). Not only is DNA methylation important in the regulation of Pref- 1 expression, but modification of histones also plays a role in expression of these imprinted genes. With regard to Pref- 1 repression during adipogenesis, a recent study revealed that a decreased level of $\mathrm{H} 3 \mathrm{~K} 4$ tri-methylation (55) leads to de-repression of Pref-1, and the Pref1 locus exhibits lower levels of active chromatin makers, such as $\mathrm{H} 3 \mathrm{~K} 4$ tri-methylation as well as $\mathrm{H} 3$ and $\mathrm{H} 4$ acetylation in 10T1/2 cells compared to committed 3T3-L1 preadipocytes. Furthermore, the Pref-1 gene showed a predominant enrichment of H3 K27 trimethylation, demonstrating that these repressive marks play a role in silencing Pref-1 gene expression in 10T1/2 cells $(56,57)$.

Regulation of adipogenesis by certain growth factors has been reported to be through modulating Pref-1 levels. Thus, growth hormone has been previously reported to maintain high levels of Pref-1 in 3T3-L1 cells to prevent differentiation of preadipocytes $(58,59)$. Furthermore, growth hormone stimulates production of Insulin-like growth factor-1 (IGF-1), which is reduced by Pref-1 treatment, showing the ability of Pref-1 to regulate growth hormone levels (60). It has also been suggested that IGF-1 may be able to bypass the inhibition of Pref-1 on adipocyte differentiation of 3T3-L1 cells (61). Interestingly, in human patients with anorexia nervosa, there was an increased level of Pref-1, which correlated to an increased number of undifferentiated cells with a corresponding decrease in BAT mass (62). Furthermore, these patients

\section{REFERENCES}

1. Rosen ED, Spiegelman BM. Molecular regulation of adipogenesis. Annu Rev Cell Dev Biol (2000) 16:145-71. doi:10.1146/annurev.cellbio.16. 1.145

2. Gregoire FM, Smas CM, Sul HS. Understanding adipocyte differentiation. Physiol Rev (1998) 78:783-809.

3. Liu J, Wang H, Zuo Y, Farmer SR. Functional interaction between peroxisome proliferator-activated receptor gamma and beta-catenin. Mol Cell Biol (2006) 26:5827-37. doi:10.1128/MCB.00441-06

4. MacDougald OA, Mandrup S. Adipogenesis: forces that tip the scales. Trends Endocrinol Metab (2002) 13:5-11. doi:10.1016/S10432760(01)00517-3
5. Rosen ED, MacDougald A. Adipocyte differentiation from the inside out. Nat Rev (2006) 7:885-96. doi:10.1038/nrm2066

6. Farmer SR. Transcriptional control of adipocyte formation. Cell Metab (2006) 4:263-73. doi:10.1016/j.cmet.2006.07.001

7. Yeh WC, Cao Z, Classon M, McKnight SL. Cascade regulation of terminal adipocyte differentiation by three members of the C/EBP family of leucine zipper proteins. Genes Dev (1995) 9:168-81. doi:10.1101/gad.9.2.168

8. Gupta RK, Mepani RJ, Kleiner S, Lo JC, Khandekar MJ, Cohen P, et al. Zfp423 expression identifies committed preadipocytes and localizes to adipose endothelial and perivascular cells. Cell Metab (2012) 15:230-9. doi:10.1016/j.cmet.2012.01.010

have low gonadal steroids and treating adolescent female anorexia nervosa with estradiol caused a significant decrease in Pref-1 levels (63). In postmenopausal women, estrogen deficiency leads to increased serum levels of Pref-1, which is associated with bone loss, and could be normalized with estrogen replacement therapy (64). Overall, there seems to be evidence of estrogen regulation of Pref-1 expression, which plays a role in regulating homeostasis of adipocyte as well as osteocyte abundance.

\section{CONCLUSION}

Obesity is characterized by increased adipose tissue through both hypertrophy and hyperplasia, and much interest has been garnered to understand the regulation of this process. In this regard, Pref- 1 has been used as a preadipocyte marker, and is notable in its ability to prevent adipocyte differentiation in an autocrine/paracrine manner. Pref- 1 interacts with fibronectin and activates MEK/ERK to induce Sox9 expression, which blocks adipocyte differentiation by binding to the promoter regions of $\mathrm{C} / \mathrm{EBP} \beta$ and $\mathrm{C} / \mathrm{EBP} \delta$ and preventing activation of $\mathrm{C} / \mathrm{EBP} \alpha$ and $\operatorname{PPAR} \gamma$. Several hormones and other cytokines have been suggested to either regulate or be regulated by Pref-1, further suggesting the critical role of Pref- 1 in the maintenance of the preadipocyte state. Pref- 1 expression transiently increases early during differentiation of MSCs. Pref-1 may be a valuable tool as a marker of precursor cells and we are employing Pref- 1 to label adipose precursors for lineage tracing and investigation of adipose tissue development. Additionally, given that imprinted genes function in fetal development and growth and with its effects on chondrogenesis and osteogenesis, Pref- 1 most likely functions beyond the control of adipogenesis and mesenchymal cell fate. Furthermore, Pref-1 is associated with early onset obesity in humans. Uncovering the Pref-1-fibronectin interaction has begun to shed light on the molecular mechanism underlying the function of Pref-1 and Pref-1 signaling in adipogenesis.

\section{ACKNOWLEDGMENTS}

This work was supported partially by National Institutes of Health Grant DK 50828 (to Hei Sook Sul).

9. Seale $\mathrm{P}$, Bjork $\mathrm{B}$, Yang $\mathrm{W}$ Kajimura S, Chin S, Kuang $\mathrm{S}$, et al. PRDM16 controls a brown fat/skeletal muscle switch. Nature (2008) 454:961-7. doi:10.1038/nature07182

10. Friedman JM. Leptin at $14 \mathrm{y}$ of age: an ongoing story. $A m$ J Clin Nutr (2009) 89:973S-9. doi:10.3945/ajen.2008.26788B

11. Galic S, Oakhill JS, Steinberg GR. Adipose tissue as an endocrine organ. Mol Cell Endocrinol (2010) 316:129-39. doi:10.1016/j.mce.2009.08.018

12. Coppack SW. Pro-inflammatory cytokines and adipose tissue. Proc Nutr Soc (2001) 60:349-56. doi:10.1079/PNS200 1110

13. Gálvez BG, San Martín N, Rodríguez C. TNF-alpha is required for the attraction of mesenchymal precursors to white adipose tissue in $\mathrm{Ob} / \mathrm{ob}$ mice. PLoS ONE (2009) 4:e4444. doi:10.1371/journal.pone.000 4444

14. Smas CM, Sul HS. Pref-1, a protein containing EGF-like repeats, inhibits adipocyte differentiation. Cell (1993) 73:725-34. doi:10.1016/0092 8674(93)90252-L

15. Smas CM, Chen L, Zhao L, Latasa MJ, Sul HS. Transcriptional repression of pref-1 by glucocorticoids promotes 3T3L1 adipocyte differentiation. J Biol Chem (1999) 274:12632-41. doi:10.1074/jbc.274.18.12632

16. Sul HS. Minireview: Pref1: role in adipogenesis and mesenchymal cell fate. Mol Endocrinol (2009) 23:1717-25. doi:10.1210/me.2009-0160 
17. Smas CM, Chen L, Sul HS. Cleavage of membrane-associated pref1 generates a soluble inhibitor of adipocyte differentiation. Mol Cell Biol (1997) 17:977-88.

18. Mei B, Zhao L, Chen L, Sul HS. Only the large soluble form of preadipocyte factor-1 (Pref-1), but not the small soluble and membrane forms, inhibits adipocyte differentiation: role of alternative splicing. Biochem J (2002) 364:137-44.

19. Jensen $\mathrm{CH}$, Teisner B, Højrup P, Rasmussen HB, Madsen OD, Nielsen B, et al. Studies on the isolation, structural analysis and tissue localization of fetal antigen 1 and its relation to a human adrenal-specific cDNA, pG2. Hum Reprod (1993) 8:635-41.

20. Wang Y, Sul HS. Ectodomain shedding of preadipocyte factor 1 (Pref-1) by tumor necrosis factor alpha converting enzyme (TACE) and inhibition of adipocyte differentiation. Mol Cell Biol (2006) 26:5421-35. doi:10.1128/MCB.02437-05

21. Wang Y, Sul HS. Pref-1 regulates mesenchymal cell commitment and differentiation through Sox9. Cell Metab (2009) 9:287-302. doi:10.1016/j.cmet.2009.01.013

22. Nueda M-L, Baladrón V, SánchezSolana B, Ballesteros M-A, Laborda J. The EGF-like protein dlk1 inhibits notch signaling and potentiates adipogenesis of mesenchymal cells. $J$ Mol Biol (2007) 367:1281-93. doi:10.1016/j.jmb.2006.10.043

23. Baladrón $\mathrm{V}$, Ruiz-Hidalgo $\mathrm{MJ}$, Nueda ML, Díaz-Guerra MJ, García-Ramírez JJ, Bonvini E, et al. dlk acts as a negative regulator of Notch1 activation through interactions with specific EGF-like repeats. Exp Cell Res (2005) 303:343-59. doi:10.1016/j.yexcr.2004.10.001

24. Wang Y, Zhao L, Smas C, Sul HS. Pref-1 interacts with fibronectin to inhibit adipocyte differentiation. Mol Cell Biol (2010) 30:3480-92. doi:10.1128/ MCB.00057-10

25. Fukai F, Iso T, Sekiguchi K, Miyatake N, Tsugita A, Katayama T. An amino-terminal fibronectin fragment stimulates the differentiation of ST-13 preadipocytes. Biochemistry (1993) 32:5746-51. doi:10.1021/bi00073a004

26. Spiegelman BM, Ginty CA. Fibronectin modulation of cell shape and lipogenic gene expression in 3T3adipocytes. Cell (1983) 35:657-66. doi:10.1016/00928674(83)90098-3

27. Howe AK, Aplin AE, Juliano RL. Anchorage-dependent ERK signaling - mechanisms and consequences. Curr Opin Genet Dev (2002) 12:30-5. doi:10.1016/S0959437X(01)00260-X

28. Wang Y, Kim K-A, Kim J-H, Sul HS. Pref-1, a preadipocyte secreted factor that inhibits adipogenesis. J Nutr (2006) 136:2953-6.

29. Moon YS, Smas CM, Lee K, Villena JA, Kim KH, Yun EJ, et al. Mice Lacking paternally expressed Pref-1/Dlk1 display growth retardation and accelerated adiposity. Mol Cell Biol (2002) 22:558592. doi:10.1128/MCB.22.15.55855592.2002

30. Lee K, Villena JA, Moon YS, Kim $\mathrm{KH}$, Lee S, Kang C, et al. Inhibition of adipogenesis and development of glucose intolerance by soluble preadipocyte factor-1 (Pref-1). $J$ Clin Invest (2003) 111:453-61. doi:10.1172/JCI200315924

31. Villena JA, Choi CS, Wang Y, Kim S, Hwang YJ, Kim YB, et al. Resistance to high-fat diet-induced obesity but exacerbated insulin resistance in mice overexpressing preadipocyte factor-1 (Pref-1): a new model of partial lipodystrophy. Diabetes (2008) 57:3258-66. doi:10.2337/db07-1739

32. Armengol J, Villena JA, Hondares E, Carmona MC, Sul HS, Iglesias R, et al. Pref-1 in brown adipose tissue: specific involvement in brown adipocyte differentiation and regulatory role of C/EBP $\delta$. Biochem J (2012) 443:799-810. doi:10.1042/BJ20111714

33. Carmona MC, Iglesias $\mathrm{R}$, Obregón MJ, Darlington GJ, Villarroya F, Giralt M. Mitochondrial biogenesis and thyroid status maturation in brown fat require CCAAT/enhancerbinding protein alpha. $J$ Biol Chem (2002) 277:21489-98. doi:10.1074/jbc.M201710200

34. Monteiro MC, Sanyal M, Cleary ML, Sengenès C, Bouloumié A, Dani C, et al. PBX1: a novel stagespecific regulator of adipocyte development. Stem Cells (2011) 29:1837-48. doi:10.1002/stem.737

35. Jing K, Heo JY, Song KS, Seo KS, Park JH, Kim JS, et al. Expression regulation and function of Pref-1 during adipogenesis of human mesenchymal stem cells (MSCs). Biochim Biophys Acta (2009) 1791:816-26. doi:10.1016/j.bbalip.2009.04.010

36. Han R, Kitlinska JB, Munday WR, Gallicano GI, Zukowska Z. Stress hormone epinephrine enhances adipogenesis in murine embryonic stem cells by up-regulating the neuropeptide Y system. PLoS ONE (2012) 7:e36609. doi:10. 1371/journal.pone.0036609

37. Morganstein DL, Wu P, Mane MR, Fisk NM, White R, Parker MG, et al. Human fetal mesenchymal stem cells differentiate into brown and white adipocytes: a role for ERR $\alpha$ in human UCP1 expression. Cell Res (2010) 20:434-44. doi:10.1038/cr.2010.11

38. Stern CD, Fraser SE. Tracing the lineage of tracing cell lineages. Nat Cell Biol (2001) 3:E216-8. doi:10.1038/ncb0901-e216

39. Tumbar T, Guasch G, Greco V, Blanpain C, Lowry WE, Rendl $\mathrm{M}$, et al. Defining the epithelial stem cell niche in skin. Science (2004) 303:359-63. doi:10.1126/science.1092436

40. Kretzschmar K, Watt FM. Lineage tracing. Cell (2012) 148:33-45. doi:10.1016/j

41. Tang W, Zeve D, Suh JM, Bosnakovski D, Kyba M, Hammer RE, et al. White fat progenitor cells reside in the adipose vasculature. Science (2008) 322:583-6. doi:10.1126/science.1156232

42. Tran K-V, Gealekman O, Frontini A, Zingaretti MC, Morroni $\mathrm{M}$, Giordano $\mathrm{A}$, et al. The vascular endothelium of the adipose tissue gives rise to both white and brown fat cells. Cell Metab (2012) 15:222-9. doi:10.1016/j.cmet.2012.01.008

43. Zhang Y, Daquinag AC, AmayaManzanares F, Sirin O, Tseng C, Kolonin MG. Stromal progenitor cells from endogenous adipose tissue contribute to pericytes and adipocytes that populate the tumor microenvironment. Cancer Res (2012) 72:5198-208. doi:10. 1158/0008-5472.CAN-12-0294

44. Rodeheffer MS, Birsoy K, Friedman JM. Identification of white adipocyte progenitor cells in vivo. Cell (2008) 135:240-9. doi:10.1016/j.cell.2008.09.036

45. Wermter A-K, Scherag A, Meyre D, Reichwald K, Durand E, Nguyen TT, et al. Preferential reciprocal transfer of paternal/maternal DLK1 alleles to obese children: first evidence of polar overdominance in humans. Eur $J$
Hum Genet (2008) 16:1126-34. doi:10.1038/ejhg.2008.64

46. O'Connell J, Lynch L, Hogan A, Cawood TJ, O'Shea D. Preadipocyte factor-1 is associated with metabolic profile in severe obesity. J Clin Endocrinol Metab (2011) 96:E680-4. doi:10.1210/jc.2010-2026

47. Schmidt JV, Matteson PG, Jones BK, Guan XJ, Tilghman SM. The Dlk1 and Gtl2 genes are linked and reciprocally imprinted. Genes Dev (2000) 14:1997-2002.

48. Takada S, Tevendale M, Baker J, Georgiades P, Campbell E, Freeman T, et al. Delta-like and gtl2 are reciprocally expressed, differentially methylated linked imprinted genes on mouse chromosome 12. Curr Biol (2000) 10:1135-8. doi:10.1016/S09609822(00)00704-1

49. Hagan JP, O'Neill BL, Stewart CL, Kozlov SV, Croce CM. At least ten genes define the imprinted Dlk1-Dio3 cluster on mouse chromosome 12qF1. PLoS ONE (2009) 4:e4352. doi:10.1371/journal.pone. 0004352

50. Kobayashi S, Wagatsuma $\mathrm{H}$, Ono $\mathrm{R}$, Ichikawa $\mathrm{H}$, Yamazaki M, Tashiro H, et al. Mouse Peg9/Dlk1 and human PEG9/DLK1 are paternally expressed imprinted genes closely located to the maternally expressed imprinted genes: mouse Meg3/Gtl2 and human MEG3. Genes Cells (2000) 5:1029-37. doi:10.1046/j.13652443.2000.00390.x

51. Golozoubova V, Gullberg H, Matthias A, Cannon B, Vennström B, Nedergaard J, et al. Depressed thermogenesis but competent brown adipose tissue recruitment in mice devoid of all hormone-binding thyroid hormone receptors. Mol Endocrinol (2004) 18:384-401. doi:10.1210/me.2003-0267

52. Bianco AC, Sheng XY, Silva JE. Triiodothyronine amplifies norepinephrine stimulation of uncoupling protein gene transcription by a mechanism not requiring protein synthesis. $J$ Biol Chem (1988) 263:18168-75.

53. Klaus S, Choy L, Champigny O, Cassard-Doulcier AM, Ross S, Spiegelman B, et al. Characterization of the novel brown adipocyte cell line HIB 1B. Adrenergic pathways involved in regulation of uncoupling protein gene expression. J Cell Sci (1994) $107(\mathrm{Pt}$ 1):313-9. 
54. Hernandez A, Garcia B, Obregon M-J. Gene expression from the imprinted Dio3 locus is associated with cell proliferation of cultured brown adipocytes. Endocrinology (2007) 148:396876. doi:10.1210/en.2007-0029

55. Heintzman ND, Stuart RK, Hon G, Fu Y, Ching CW, Hawkins $\mathrm{RD}$, et al. Distinct and predictive chromatin signatures of transcriptional promoters and enhancers in the human genome. Nat Genet (2007) 39:311-8. doi:10.1038/ng1966

56. Zhang Q, Ramlee MK, Brunmeir R, Villanueva CJ, Halperin D, Xu F. Dynamic and distinct histone modifications modulate the expression of key adipogenesis regulatory genes. Cell Cycle (2012) 11:4310-22. doi:10.4161/cc.22224

57. Carr MS, Yevtodiyenko A, Schmidt CL, Schmidt JV. Allele-specific histone modifications regulate expression of the Dlk1-Gtl2 imprinted domain. Genomics (2007) 89:280. doi:10.1016/j.ygeno.2006.10.005
58. Nam SY, Lobie PE. The mechanism of effect of growth hormone on preadipocyte and adipocyte function. Obesity Rev (2000) 1:73-86. doi:10.1046/j.1467789x.2000.00015.x

59. Hansen LH, Madsen B, Teisner B, Nielsen JH, Billestrup N. Characterization of the inhibitory effect of growth hormone on primary preadipocyte differentiation. $\mathrm{Mol}$ Endocrinol (1998) 12:1140-9. doi:10.1210/me.12.8.1140

60. Appelbe OK, Yevtodiyenko A, Muniz-Talavera H, Schmidt JV. Conditional deletions refine the embryonic requirement for Dlk1. Mech Dev (2013) 130:143-59. doi:10.1016/j.mod.2012.09.010

61. Zhang $\mathrm{H}$, Nøohr J, Jensen $\mathrm{CH}$, Petersen RK, Bachmann E, Teisner B, et al. Insulin-like growth factor-1/insulin bypasses Pref-1/FA1-mediated inhibition of adipocyte differentiation. J Biol Chem (2003) 278:20906-14. doi:10.1074/jbc.M300022200

62. Bredella MA, Fazeli PK, Freedman LM, Calder G, Lee H, Rosen
CJ, et al. Young women with cold-activated brown adipose tissue have higher bone mineral density and lower Pref-1 than women without brown adipose tissue: a study in women with anorexia nervosa, women recovered from anorexia nervosa, and normal-weight women. JCEM (2012) 97:E584-90. doi:10.1210/jc.2011-2246

63. Faje AT, Fazeli PK, Katzman D Miller KK, Breggia A, Rosen $C J$, et al. Inhibition of Pref1 (preadipocyte factor 1) by estradiol in adolescent girls with anorexia nervosa is associated with improvement in lumbar bone mineral density. Clin Endocrinol (Oxf) (2013) doi:10.1111/cen.12144. [Epub ahead of print].

64. Abdallah BM, Bay-Jensen AC, Srinivasan B, Tabassi NC, Garnero $\mathrm{P}$, Delaissé JM, et al. Estrogen inhibits Dlk1/FA1 production: a potential mechanism for estrogen effects on bone turnover. J Bone Miner Res
(2011) 26:2548-51. doi:10.1002/ jbmr.444

Conflict of Interest Statement: The authors declare that the research was conducted in the absence of any commercial or financial relationships that could be construed as a potential conflict of interest.

Received: 30 April 2013; paper pending published: 23 May 2013; accepted: 19 June 2013; published online: 03 July 2013. Citation: Hudak CS and Sul HS (2013) Pref-1, a gatekeeper of adipogenesis. Front. Endocrinol. 4:79. doi: 10.3389/fendo.2013.00079

This article was submitted to Frontiers in Experimental Endocrinology, a specialty of Frontiers in Endocrinology.

Copyright (C) 2013 Hudak and Sul. This is an open-access article distributed under the terms of the Creative Commons Attribution License, which permits use, distribution and reproduction in other forums, provided the original authors and source are credited and subject to any copyright notices concerning any third-party graphics etc. 